\title{
A Framework for the Promotion of Tourism Industry Using Blockchain Technology
}

\author{
Daniel Mago Vistro ${ }^{1, *}$, Muhammad Shoaib Farooq ${ }^{2}$, Attique Ur Rehman ${ }^{2}$, and \\ Muhammad Bilal ${ }^{2}$ \\ ${ }^{I}$ School of Computing, Asia Pacific University, Kuala lumpur, Malaysia. \\ ${ }^{2}$ School of System and Technology, University of Management and Technology, Pakistan. \\ Department of Computer Science, Lahore Garrison University, Lahore, Pakistan. \\ "Corresponding author.Email: Daniel.mago@staffemail.apu.edu.my
}

\begin{abstract}
The best interconnected profitable projects, tourism has come a long way since the technology allows tourists to watch \& make their journeys without the necessity to go a tourism company because Blockchain has potential to transform this Industry. With the advancement of Internet marketing, visitors are able to access and view the information in the real time on their gadgets such as Laptops, Computers, Tablets, \& Smartphones and as a result they can select their own contents. One of the strong growing technologies and the most cutting edge technologies is tourism blockchain. The Blockchain offers many advantages to the tourism business as it can help to the increase profitability, improvement of the customer satisfaction $\&$ to improve the performance. In this paper, I present the current situation in Pakistan regarding the utilization the technology of blockchain in tourism business. The agenda of this paper includes discovery of why blockchain technology couldn't be used in tourism business, and what tasks should be managed.
\end{abstract}

Keywords: E-Tourism, Hospitality, Tourism Management, Tourism, Smart Contracts, Distributed ledger technology.

\section{INTRODUCTION}

The tourism business represents the key sectors of global economic development. The globally recognized tourism definition is that which suggests that tourism consists of the activities of travelers living in and out of their normal conditions for more than 1 successive year of relief, trading and more unrelated tasks [1]. In 2019, the total investment of the tourist business in global economy is USD 9.9 trillion [2], representing $11.3 \%$ of GDP, $6.6 \%$ of exports, and $27.3 \%$ of exports and $-10 \%$ of land tenure. It is necessary to note that, in this report, Tourism department expects more growth of $3.6 \%$ by 2019 , exceeding the estimated global economic growth of $2.8 \%$. Tourism has modified dramatically when the Internet gave opportunity to the travelers to search and plan their travel without the hassle of the travel company visit [18-25]. The tourism industry will soon change with the advent of digital technology, which will result in a shift in the needs and needs of travelers in terms of tourism services and products [3].

This tourism industry involves with some companies and sectors to achieve their goal. It contains (i) Transportation, this includes flight and railways reservations, spacecraft and many more. (ii) Accommodation, it includes Hotels reservation, Cruises, Breakfast. (iii) Food and Beverage, it involves in catering, Nightclubs, Restaurants, Bars etc. (iv) Entertainment, this sector includes shopping, casino, Tourist Guides. (v) Other linked Companies, like Travel agencies, Education sector and more [4].

As a new technology, the blockchain [26-30] is change in all zones, even tourism. Blockchain technology provide opportunities to different companies to do business in honest way without the need for a centralized control 
system [5]. This is a new way of processing information , editing, and recording with long-lasting blocks, that are reliable and functional [6]. The utilization of blockchain technology in the tourism can lead to lower costs associated with currency exchange rates and its simplify the loyalty programs for regular travelers [7]. Researchers are looking for ways to address these changes in the tourism business [8].

The main purpose of research is to examine the tourism business in the context of blockchain technology and to check if companies in Pakistan consider their use in their day-to-day tasks. This technology is the new technology in the market that's why this technology is embraced by the customers. Blockchain technology has adopted very fastly by customers like other technologies. It is necessary to highlight the entire business is still learning about the use of specified technologies and few technology applications through the system. Blockchain is accepted widely so it is important to explain how this technology can be helpful in the business. After this, the other part of my paper is that the LR relevant to the utilization of blockchain technology on context of tourism Industry. Some e.g. of blockchain revolution use in world widely are explained in third section. And in the section 4, we examine the utilization of this technology in tourist business.

\section{TOURISM INDUSTRY USING BLOCKCHAIN - RELATED WORK}

The occurrence of this technology and its well-known product has attracted media attention and generated wide interest in many businesses. Tourism TUI has accepted Blockchain for its reservation, booking, and payment systems [9] and has made important investments in the regions [10]. With the help of social media platforms, people can share our experience with others. This can cause problems as there is a possibility of scams or fake reviews. Blockchain can be used to fix by its features like privacy, trust, transparency and security [11]. The tourism sector was the leading investor in blockchain in 2018 [12], by which time the trend is expected to continue in three years. The importance of the blockchain to the tourism sector this can increase the scholars interest. Block chain's commercial use moves beyond the experimental provide solution to real world problem in the huge world Company [13]. Blockchain technology have enough potential apps for other industries and they impact on other stakeholders. As we shown in fig 1 , shows the opportunities for many people in tourist industry.

Blockchain is versatile and its application always enhances tourism: (i) It enhances the passenger experience with this platform, (ii) Payments through Blockchain are fast and hassle free over cross border, (iii) Blockchain use facilitates diversity, protects currency \& strengthens banking system, (iv) Block chain contributes to reducing overall operating costs [14].

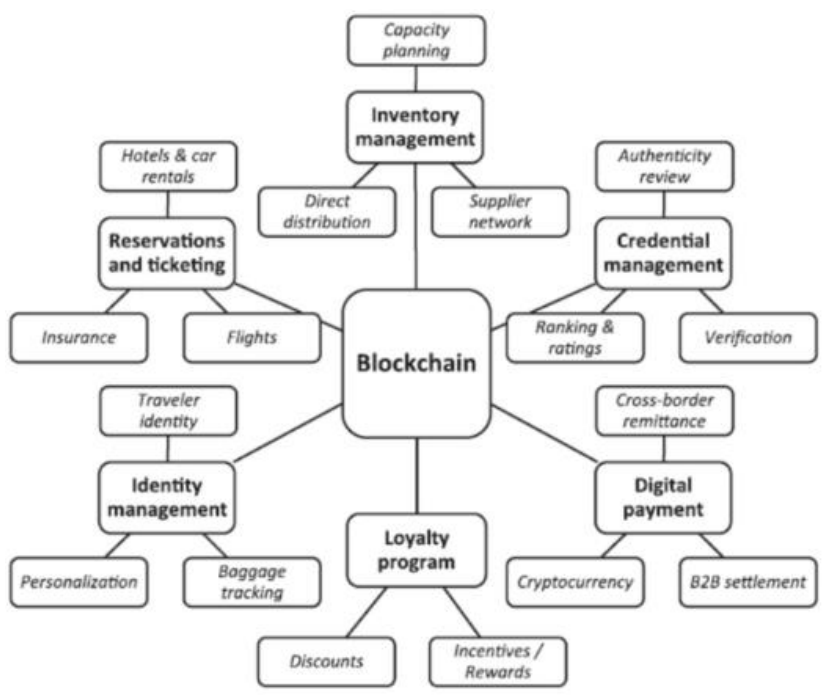

Figure 1 Block chain applications for Tourism

The block chain second generation related trend towards blockchain development and the smart contracts uses will increase the advantages to traveler. It has been confirmed that smart cities and Smart Tourism share a similar structure. Both Smart Tourism \& smart city architecture has 6 layers, in Table 1.

Table 1. Characteristics of Tourism and Smart City with Blockchain [15]

\begin{tabular}{|c|c|c|}
\hline Layer & SC Components & $\begin{array}{l}\text { Blockchain } \\
\text { Technology } \\
\text { components }\end{array}$ \\
\hline Data & Urban data & $\begin{array}{l}\text { Distributed } \\
\text { hyperledger } \mathrm{db}\end{array}$ \\
\hline Policy & $\begin{array}{l}\text { Governance, } \\
\text { Process, Structure }\end{array}$ & $\begin{array}{l}\text { Extra policy for } \\
\text { blockchain } \\
\text { business. }\end{array}$ \\
\hline Platform & $\begin{array}{l}\text { Platform services like cloud, } \\
\text { application and open APIs. }\end{array}$ & $\begin{array}{l}\text { Diverse crypto } \\
\text { currencies and } \\
\text { smart contracts } \\
\text { DApps. }\end{array}$ \\
\hline Traveler & $\begin{array}{l}\text { Shopping, Restaurant, } \\
\text { Accommodation, } \\
\text { Entertainment, Transportation }\end{array}$ & Same as SC. \\
\hline Citizen & $\begin{array}{l}\text { Innovation \& } \text { Economy, } \\
\text { Culture \& Entertainment, } \\
\text { Citizenship \& Community, } \\
\text { Urban Places \& spaces, } \\
\text { Transport \& Management. }\end{array}$ & Same as SC. \\
\hline IT & $\begin{array}{l}\text { The same Infrastructure } \\
\text { components of SC. }\end{array}$ & $\begin{array}{l}\text { Ubiquitous city } \\
\text { Network }\end{array}$ \\
\hline
\end{tabular}

On the behalf of Table 1, we conclude that the civilian layers in ST on below the passenger layers and layer: 1, 2, 3, 4 share similar components. Tourism adopts 
technology's that affects \& transforms today's businesses [15]. Based on the analysis, three areas of modifications have been identified: (i) Price reduction, (ii) Receive Crypto currency, (iii) New Eco. System development.

The blockchain use in the tourism sector facilitates many processes that ordinary tourists have to do while conducting their tours. And these trips include arrival, booking, and accommodation. Blockchain technology is decentralized network, a customer must verify it only one time before boarding, because all passenger information and transactions are scattered across multiple locations across multiple locations. There are many benefits of blockchain in tourism business and hospitality. Among them are: (i) Speedily the transactions and view the previous transactions, (ii) Secure \& transparent transactions, (iii) Customer Improve customer / guest satisfaction. All passenger information and transactions are scattered, (iv) Blockchain Raising and promoting levels of trust and confidence among participants [16]. This technology in hospitality and tourism business and identifies the following zones [17]: (i) Payment, (ii) Cryptocurrency, (iii) Tracking and service optimization, (iv) Payment, (v) Verified rating and review system, (vi) Smart Contract, (vii) Initiative cooperative initiative and appropriate attention, (viii) Cancellation of Tourism and Hospitality Activities.

As investment in blockchain for tourism business increases, it is expected that these reforms significantly affect the future of tourism. Therefore, the blockchain technology in the field of tourism from various angles and to make appropriate and in-depth research proposals and explanations [17]

\section{METHODOLOGY}

This research that was resulted on the base of the utilization of blockchain in tourist business. For empirical part the current situation on use of blockchain in tourist sector \& secondary data was inspect while for the theoretical framework scientifically and professionals papers was inspect. We compared all data in tourism business in use of block chain technology that it creates the role in the national economy of country. The tourism department is still inadequate researched in use of blockchain technology. In my research, I gathered the secondary data that was gathered by online forums, searches using phrase: "Blockchain in Tourism Pakistan". It means the online searches are under study. I gather the data analyse the country (Pakistan) \& according the result, we conclude that other Countries in this region where Pakistan is located are similar. We also examined the Pakistan that the important limitations are data availability, till there is no any kind of successful example available Tourism using blockchain technology.
Creating a public ledger of suppliers and customers in the travel Industry. This public ledger built by Blockchain is available not only to big companies, but also for small companies. System need the following entities: (i) Defining the currency exchange program, (ii) Maintain and control the data, (iii) Assurance that the venue will be fair. The status of blockchain for trusted prog provides an opportunity to highlight the importance of power distribution.

The tourism business in Pakistan play an important role in national economy. In my research, we gather data collection through online platforms using the phrases: "Tourism in Pakistan. Based on the search results, I present some of the apps available in terms of understanding the country and infrastructure relevant to basic implementation.

\section{CONCLUSION}

Blockchain development and the use of smart contracts will further enhance the benefits to customers. The blockchain simplifies \& speedily check the passengers at airports, railway stations and all other transports sectors. The investment in block chain in tourism industry starts increases, it will impact on Tourism future and how things are managed. Tourism becomes a trend accessible to millions every day. The faster communication is on the base of IT. Tourism is defined by two basic stakeholders: tourists and tourism who want to earn money. In this research I highlight the evidence of Tourism industry in Blockchain Technology, but in the previous work we find the example of blockchain in Tourism. The complete analysis of implementation of blockchain in tourism business is required to access the application of blockchain in tourism. Therefore, the objective of this search is to launch, reviews and show the powerful areas, which is popular for tourism, along with country Pakistan review. In Pakistan, there is no use of till now web of 3.0. This 3rd gen decentralized network means that the user is a user that everyone can join in without fear. The main reasons for the less experience of blockchain technology are the following: inefficiency of system control, need to aware the tourists about the importance of blockchain technology, inexperience of infrastructure. This technology is a challenge in the tourist development of the national economy. Situation of Pakistan, we can generally conclude that efforts to implement blockchain nodes, especially in the transformation of business models, should focus on building a door-to-door blockchain ecosystem. On the basis of current situation, I hope this paper will be very helpful for the entrepreneurs about the use of blockchain technology in tourism business. 


\section{REFERENCES}

[1] C. C. J. F. D. G. R. S. S. Wanhill, "Tourism: principles and practice," vol. 2nd ed., 1998.

[2] Khan, N. S., Abid, A., Abid, K., Farooq, U., Farooq, M. S., \& Jameel, H. (2020). Speak Pakistan: Challenges in developing Pakistan sign language using information technology. South Asian Studies, $30(2$.

[3] V. Kazandzhieva, H. Santana, and A. Prof, "Etourism: Definition, development and conceptual framework," Dec. 2019.

[4] Vistro, D. M., Rehman, A. U., Abid, A., Farooq, M. S., \& Idrees, M. (2020). A SURVEY ON INTERNET OF VEHICLES (IOV) WITH INTELLIGENT TRANSPORT SYSTEM USING CLOUD SERVICES. Journal of Critical Reviews, 7(9), 16601672.

[5] K. R. Iansiti, M.; Lakhanii, "The Truth About the Blockchain. Harv. Bus. Rev,” vol. 95, pp. 118-127, 2017.

[6] Aziz, O., Farooq, M. S., Abid, A., Saher, R., \& Aslam, N. (2020). Research trends in enterprise service bus (ESB) applications: a systematic mapping study. IEEE Access, 8, 31180-31197

[7] A. J. Kowalewski, D.; McLaughlin, J.; Hill, "Blockchain Will Transform Customer Loyalty Programs.," [Online]. Available: https://hbr.org/2017/03/blockchain-will-transformcustomer-loyalty-programs.

[8] I. Ozdemir, A.I.; Ar, I.M.; Erol, "Assessment of blockchain applications in travel and tourism.," vol. 53, pp. 1-15, 2019.

[9] B. Manager., "TUI Tourism Group Will Adopt Ethereum Blockchain Technology.," [Online]. Available: https://btcmanager.com/tui-tourism-groupto-adopt-ethereums-blockchain/.

[10] 13. Vistro, D. M., Rehman, A. U., Abid, A., Farooq, M. S., \& Idrees, M. (2020). ANALYSIS OF CLOUD COMPUTING BASED BLOCKCHAIN ISSUES AND CHALLENGES. Journal of Critical Reviews, 7(10), 1482-1492.

[11] A. Erceg, J. Damoska, and I. Kelić, "Blockchain in the Tourism Industry - A Review of the Situation in Croatia and Macedonia," Informatics, vol. 7, Feb. 2020, doi: 10.3390/informatics7010005.
[12] B. Manager, "Etherum Technology will adopt by TUI group," [Online]. Available: https://btcmanager.com/news/blockchain/.

[13] CoinDesk, "Blockchain compelling case for Big Companies," 2019, [Online]. Available: https://www.coindesk.com/deloitte-3-out-of-4-bigcompanies-see-compelling-case-for-blockchain.

[14] A. O. J. Kwok and S. G. M. Koh, "Is blockchain technology a watershed for tourism development?," Curr. Issues Tour., vol. 22, no. 20, pp. 2447-2452, Dec. 2019, doi: 10.1080/13683500.2018.1513460.

[15] K. Nam, C. S. Dutt, P. Chathoth, and M. S. Khan, "Blockchain technology for smart city and smart tourism: latest trends and challenges," Asia Pacific J. Tour. Res., pp. 1-15, Feb. 2019, doi: 10.1080/10941665.2019.1585376.

[16] W. Paul, "Can all sectors of the hospitality and tourism industry be influenced by the innovation of Blockchain technology?," Worldw. Hosp. Tour. Themes, vol. 11, no. 2, pp. 112-120, Jan. 2019, doi: 10.1108/WHATT-11-2018-0077.

[17] I. Önder and H. Treiblmaier, "Blockchain and tourism: Three research propositions," Ann. Tour. Res., vol. 72, no. C, pp. 180-182, 2018, doi: DOI: 10.1016/j.annals.2018.03

[18] Prabu, S., Balamurugan, V. and Vengatesan, K., 2019. Design of cognitive image filters for suppression of noise level in medical images. Measurement, 141, pp.296-301.

[19] Shivappriya, S.N., Karthikeyan, S., Prabu, S., Pérez de Prado, R. and Parameshachari, B.D., 2020. A modified ABC-SQP-based combined approach for the optimization of a parallel hybrid electric vehicle. Energies, 13(17), p.4529.

[20] Jagannathan, P., Rajkumar, S., Frnda, J., Divakarachari, P.B. and Subramani, P., 2021. Moving Vehicle Detection and Classification Using Gaussian Mixture Model and Ensemble Deep Learning Technique. Wireless Communications and Mobile Computing, 2021.

[21] Shivappriya, S.N., Priyadarsini, M., Stateczny, A., Puttamadappa, C. and Parameshachari, B.D., 2021. Cascade object detection and remote sensing object detection method based on trainable activation function. Remote Sensing, 13(2), p.200.

[22] Kiran, P., Parameshachari, B.D., Yashwanth, J. and Bharath, K.N., 2021. Offline Signature Recognition Using Image Processing Techniques and Back 
Propagation Neuron Network System. SN Computer Science, 2(3), pp.1-8.

[23] Le, N.T., Wang, J.W., Wang, C.C. and Nguyen, T.N., 2019. Automatic defect inspection for coated eyeglass based on symmetrized energy analysis of color channels. Symmetry, 11(12), p.1518.

[24] Nguyen, N.T., Liu, B.H. and Weng, H.Z., 2018, May. A distributed algorithm: Minimum-latency collisionavoidance multiple-data-aggregation scheduling in multi-channel WSNs. In 2018 IEEE International Conference on Communications (ICC) (pp. 1-6). IEEE.

[25] Karuppusamy, P., Perikos, I., Shi, F. and Nguyen, T.N., 2020. Sustainable communication networks and application. Lecture Notes on Data Engineering and Communications Technologies, pp.65-72.

[26] L. Tan, N. Shi, K. Yu, M. Aloqaily, Y. Jararweh, “A Blockchain-Empowered Access Control Framework for Smart Devices in Green Internet of Things", ACM Transactions on Internet Technology, vol. 21, no. 3, pp. 1-20, 2021,https://doi.org/10.1145/3433542.

[27] K. Yu, L. Tan, M. Aloqaily, H. Yang, and Y. Jararweh, "Blockchain-Enhanced Data Sharing with Traceable and Direct Revocation in IIoT", IEEE Transactions on Industrial Informatics, doi: 10.1109/TII.2021.3049141.

[28] K. Yu, L. Tan, X. Shang, J. Huang, G. Srivastava and P. Chatterjee, "Efficient and Privacy-Preserving Medical Research Support Platform Against COVID19: A Blockchain-Based Approach”, IEEE Consumer Electronics Magazine, doi: 10.1109/MCE.2020.3035520.

[29] L. Tan, H. Xiao, K. Yu, M. Aloqaily, Y. Jararweh, “A Blockchain-empowered Crowdsourcing System for 5G-enabled Smart Cities", Computer Standards \& Interfaces, https://doi.org/10.1016/j.csi.2021.103517

[30] N. Shi, L. Tan, W. Li, X. Qi, K. Yu, "A BlockchainEmpowered AAA Scheme in the Large-Scale HetNet", Digital Communications and Networks, https://doi.org/10.1016/j.dcan.2020.10.002. 